Article

\title{
Revisiting M\&M with Taxes: An Alternative Equilibrating Process
}

\author{
Kenneth J. Kopecky ${ }^{1, *}$, Zhichuan (Frank) Li ${ }^{2, *}$, Timothy F. Sugrue ${ }^{3}$ and Alan L. Tucker ${ }^{4}$ \\ 1 Department of Finance, Fox School of Business, Temple University, Philadelphia, PA 19122, USA \\ 2 Department of Finance, Ivey Business School, University of Western Ontario, London, ON N6G 0N1, Canada \\ 3 Department of Finance, School of Business, Clarkson University, Potsdam, NY 13699, USA; \\ tsugrue@clarkson.edu \\ 4 Independent Researcher, Newtown, PA 18940, USA; dralantucker@yahoo.com \\ * Correspondence: kkopecky@temple.edu (K.J.K.); fli@ivey.ca (Z.L.); \\ Tel.: +1-386-957-3372 (K.J.K.); +1-519-661-4112 (Z.L.)
}

Received: 24 October 2017; Accepted: 8 January 2018; Published: 16 January 2018

\begin{abstract}
Modigliani and Miller present an equity-quantity shifting equilibrating process to achieve an optimal firm value in the presence of corporate taxes. However, in the era in which they derived their various propositions regarding the relation between a firm's value and its capital structure, well-capitalized takeover specialists including private equity firms and sovereign funds did not exist, at least by today's standards. In this paper we develop a simple arbitrage strategy, made viable by the presence of takeover firms, which presents an alternative equilibrating process to achieve the same optimal firm value. This alternative process is markedly different from that of the Modigliani and Miller theorem in terms of its predictions for debt use and restores the prospect of capital structure irrelevancy despite the existence of corporate taxes.
\end{abstract}

Keywords: capital structure; debt; interest deduction; equity price adjustment

JEL Classification: G30; G32

\section{Introduction}

In their seminal paper, Modigliani and Miller (1963) ("MM63" hereafter) demonstrate that in the presence of corporate taxes with the ability to expense the interest paid on its debt, a firm's value is maximized by all-debt financing. To achieve their corner solution equilibrium, MM63 tacitly rely on the existence of a liquid debt market. Firms can readily lever their capital structure by issuing debt and retiring equity in a strategy that may be aptly described as "equity-quantity shifting". The issuance of debt necessitates a competitive credit market, i.e., one that is "deep" or price elastic. Given the existence of organized debt markets with large institutional participants at the time, MM63's reliance on an equity-quantity shifting equilibrating process is clearly reasonable.

However, capital markets have changed considerably since the era in which Modigliani and Miller ("MM") derived their various propositions regarding capital structure. Such change motivates us to investigate whether MM63's equity-quantity shifting equilibrating process is unique, or instead if the same optimal firm value can be obtained via an alternative no-arbitrage process. A major change in capital markets is the advent of well-capitalized takeover firms including private equity firms and sovereign funds. These entities did not exist during the MM era, at least by today's standards. In this paper we demonstrate that the existence of such entities gives rise to a viable alternative equilibrating process that we dub "equity-price shifting". As demonstrated herein, this alternative no-arbitrage process is as straightforward and achievable as the equity-quantity shifting process of MM63, and it leads to the same optimal firm value. 
The intuition behind our approach is simple, and is grounded in sound economic theory as old as that of Pareto: If a firm " $X$ " is under-levered, a private equity firm " $Y$ " will be incentivized to buy $X^{\prime}$ 's stock and optimally re-capitalize firm $X$. However, in an efficient equity market the stock price of firm $X$ will reflect the takeover pressure, which logically implies that the presumably lost value due to under-leverage is already captured in firm X's stock price. Thus, there is no need to actually issue debt. To use an analogy, Pareto's theory demonstrates that if there are two fields, one with crops and the other fallow, the fallow field will command a nearly equal price to the one with crops because of the prospect of sowing and reaping the fallow field. Importantly, one does not have to actually grow crops on the fallow field in order for its market value to remain close to that of the other field. The mere prospect of growing crops will ensure a small difference in values, if viable buyers of the fallow field exist. Similarly, the difference between the values of two firms, one levered and one not, will be small in the presence of corporate taxes, even if the latter firm remains unlevered, because of the prospect of levering the all-equity firm, i.e., the existence of a viable takeover entity that will buy and financially restructure the under-levered firm. In the era of MM, there were few takeover entities. Thus, an equity quantity-shifting process, i.e., actual debt issuance, was required to optimize firm value. However, today's markets are replete with well-financed takeover firms and active take-over markets now exist in many countries. As perverse as it may initially seem, in today's market environment we do not actually require the issuance of debt in order to capture the value presented by the debt-induced interest tax credit-just as we do not need to actually grow crops in order for our fallow field to command a value close to that of a field with crops. The benefit of the interest debt shield may be already reflected in the equity component of a firm's value.

If the equity-quantity shifting mechanism of MM63 and our equity-price shifting mechanism both lead to the same optimal firm value, then why might one be interested in the equity-price shifting process? The answer to this question lies in its consequences for observed debt use. It has been observed that, contrary to the implications of the traditional static tradeoff model of capital structure choice, many corporations appear to possess sub-optimal capital structures because they do not fully utilize the debt tax shield (cf. Miller 1977; Graham 2000). Explanations advanced to resolve this under-leverage puzzle have focused on leverage mis-measurement (cf. Welch 2011) and distress costs mis-measurement (cf. Almeida and Philippon 2007); the existence, but empirical omission, of non-debt tax shields including tax shelters (cf. Graham and Tucker 2006; Lin et al. 2014) and pension contributions (cf. Shivdasani and Stefanescu 2010); and the omission of international tax considerations (cf. Huizinga et al. 2008). In this paper we propose an alternative theoretical explanation to this empirical puzzle that is unrelated to the aforementioned explanations. More specifically, we present a partial equilibrium debt tradeoff model that, through the introduction of a takeover market and a simple trading strategy, demonstrates the optimality of lower leverage for a cohort of firms, and, moreover, that this apparently sub-optimal capital structure can persist even in the absence of any special debt-corporate conflicts. The cohort of firms is likely to consist of firms whose equity can be absorbed by potential acquirers such as private equity firms. ${ }^{1}$

The above result depends on two reasonable assumptions: First, a friction exists in the form of a fixed cost associated with corporate recapitalization. Second, there exists today a takeover market that is reasonably competitive and efficient. ${ }^{2}$ Given these two assumptions we show that the stock

1 The equilibrating force presented in this paper does not require the takeover firm to be a private equity firm. Other institutional investors are potential candidates. Moreover, still other investors-knowing that private equity and other takeover firms may act-may be incentivized to purchase the stocks of the sub-optimally capitalized firms, thus providing for an overall larger pool of capital to finance the purchase of these stocks.

2 The notion that external markets can influence the investing, financing, and other decisions of a firm (and, therefore, its value) is not novel. For example, the existence of a hostile takeover market is often cited as a reason for managers to limit their costly agency behaviors. Also, the equilibrating process in standard tradeoff models relies on the existence of a deep external debt marketplace that allows firms to increase their leverage in order to pocket the interest tax shield associated with debt financing. 
value of a firm that does not recapitalize in the presence of a tax shield is not necessarily determined by the standard discounted cash flow model. Furthermore, we show that the fixed internal cost of recapitalization, paid either explicitly or implicitly with the firm's resources, may be only one component of the recapitalization cost perceived by the firm. Even if this internal cost is known and it appears optimal to recapitalize internally, a firm may nonetheless opt to remain with an apparently sub-optimal capital structure. In this regard, our model also provides insight into the observed rigidity of within-firm capital structures (cf. Fama and French 2002), at least for a cohort of firms.

As their name suggests, tradeoff models attempt to determine an optimal capital structure by weighing the costs and benefits of debt utilization. Empirically, tradeoff models-either static or dynamic, and whether estimated at the cross-sectional or within-firm level-have largely provided an inadequate fit for the data. A prominent work by Graham and Leary (2011) reviews the major theories, including trade-off theory and its shortcomings; it is important to study the trade-off theory further as it maintains a prominent position, to this day, in the literature, textbooks, and classroom. Our theory is unique (despite the empirical attacks) because it speaks to a limitation of the theory that is theoretical in nature. To the best of our knowledge, no theory has recognized that the original equilibrium is not necessarily a unique one, and that if this were to have been recognized originally, then the trade-off theory may have taken a less prominent position in the literature, and that subsequent empirical findings (weakness in the theory's empirical fit) may have been less puzzling. Graham and Leary (2011) has a section on why the trade-off theory has struggled (variable mis-measurement, etc.). This paper adds another item to their list-namely that the theory predictions are tempered in light of the equity price-shifting equilibrium.

In this paper we present a model that perhaps can partly explain the lack of strong empirical confirmation of the tradeoff model. Essentially, previous tradeoff models omit the possibility that-at least for some firms - a portion of the benefits of debt usage may be captured by a shift in the equity values of these firms, without a change in their debt usage. Such a combination-a shift in equity values and unchanged debt usage-would imply that for this cohort of firms, low leverage is optimal. ${ }^{3}$ Thus, at the cross-sectional level, the under-leverage puzzle may not be as problematic as once thought. By aggregating the cohort of firms, for which low debt is optimal, with other firms, for which higher debt is optimal, researchers, when testing tradeoff models cross-sectionally, have perhaps biased their findings against the standard model's prediction of higher debt utilization. Furthermore, because persistence in leverage at the within-firm level is correlated with low debt usage, our model may help to explain the sticky-debt puzzle. ${ }^{4}$

The paper is organized as follows. Section 2 provides a brief review of the under-leverage and sticky debt puzzles. A standard debt tradeoff model is presented in Section 3 and extended in Section 4 to analyze the effects of both recapitalization costs and the presence of an active takeover market. A brief conclusion is presented in Section 5 .

\section{Under-Leverage and Sticky Debt Puzzles}

The under-leverage puzzle ${ }^{5}$ refers to the apparent underutilization of debt in light of the tax advantage occasioned by leverage. This phenomenon was first noted by Miller (1977) and

3 While we focus our analysis on a shift in equity value combined with no change in debt usage; the analysis can be readily modified to accommodate a "blended" equilibrium capital structure occasioned by a smaller shift in equity value combined with some increase in debt usage. The under-leverage and sticky debt puzzles continue to be partly explained, at least for a cohort of firms, in this blended, equilibrating approach.

4 Again, we emphasize that these arguments might hold only for a cohort of firms-likely smaller firms whose equity purchase can be more readily financed by private equity and other takeover firms. However, the analysis may be applicable to larger firms if just a fraction of their outstanding stock is required to be purchased in order to gain outright control of their financing decisions.

5 This puzzle goes by other names; Graham (2000) called it "debt conservatism" and Miller (1977) referred to it as "horse and rabbit stew". 
thereafter addressed more rigorously by Parrino and Weisbach (1999) and, especially, Graham (2000). An anecdote that firms appear to be under-levered can be found in Graham and Tucker (2006), who report that during the early 1990's Compaq Computer Corporation could have saved $\$ 22$ million annually in federal tax payments had it increased its total debt from just $1.3 \%$ of total assets to an industry comparable level of $25 \%$. Graham (2000) contends that the average magnitude of debt usage is small relative to the tax benefits of debt as evidenced, for example, by the small ratio of interest deductions to expected income. ${ }^{6}$ Researchers have attempted to resolve this apparent puzzle from different perspectives. One explanation has focused on the existence of non-tax tax shields as first discussed by DeAngelo and Masulis (1980). The existence of these shields may explain, at least in part, the low use of debt because the shields effectively substitute for the benefits of the interest deduction from debt financing. For example, Graham and Tucker (2006) show that firms engaging in tax sheltering have lower leverage than non-sheltering firms. Additional research on non-debt tax shields includes the general level of tax haven activity suggested by the gap between book and tax income (cf. Desai and Dharmapala 2009), employee stock option plans (Graham et al. 2004), and pension contributions (Shivdasani and Stefanescu 2010). Other explanations of under-leverage focus on leverage and distress costs mis-measurement (cf. Welch 2011; Almeida and Philippon 2007), international tax considerations for multinationals (Huizinga et al. 2008), and intertemporal macroeconomic risk. ${ }^{7}$

Under-leveraging-if it in fact exists—can be viewed as a potential shortcoming of the static tradeoff model at the cross-sectional level. At the time series level, the sticky debt puzzle refers to the surprisingly stable secular pattern of corporate debt usage despite vast changes in corporate tax policy - a phenomenon that dates back to the very advent of corporate taxes in the early twentieth century. For example, Taggart (1985) reports that aggregate corporate leverage actually decreased somewhat during the first decade of the tax code's existence and that although the largest increases in corporate debt financing occurred during the 1970's, the net debt tax ratios of Grier and Strebel (1980) remained relatively flat during that period. Miller (1963) and Sametz (1964) also assert that the corporate debt-equity mix has exhibited remarkable secular stability. ${ }^{8}$

Several researchers have reported that capital structure also exhibits persistence at the micro level (so called "within-firm" persistence). For example, Fama and French (2002) report that individual firms' debt levels adjust very slowly to their targeted levels. ${ }^{9}$ Others reporting slow adjustment include Flannery and Rangan (2006), Kayhan and Titman (2007), and Lemmon et al. (2008). Sticky capital structures have been attributed to the cumulative outcome of historical equity market timing events rather than tax policy (Baker and Wurgler 2002), equity price shocks rather than tax policy (Welch 2004), and to the existence of investment spikes in the form, for example, of long-term debt occasioned by leveraged buyouts (Morellec and Schürhoff 2010; Tserlukevich 2008).

In contrast to the above research, the recent work of Rauh and Sufi (2010) suggests that low-credit firms have less persistence in their capital structures. Leary and Roberts (2005), in a tradeoff model, argue against the "investment spike" hypothesis. They find that the persistent effects of shocks on leverage observed in previous studies are more likely due to adjustment costs than to indifference toward capital structure. Furthermore, DeAngelo et al. (2011), in a dynamic model, advance an alternative empirical interpretation. They report that, at the firm level, capital structures are persistent in appearance because firms use short-term debt (e.g., credit lines) and not long-term

6 However, others argue that average debt ratios are not too low; see (Green and Hollifield 2003; Hennessy and Whited 2005; Ju et al. 2005).

7 See Graham and Leary (2011) for additional references.

8 Graham and Narasimhan (2004) document that debt ratios fell by about one third during the Great Depression, suggesting that debt usage may partly reflect managers' personal experiences. Unfortunately, the literature addressing the persistence of debt levels across vast changes in corporate tax regimes is sparse.

9 However, several researchers aver that the speed of adjustment coefficient estimates in Fama and French (2002) are not statistically reliable. Also, some argue that partial adjustment models of within-firm capital structure are too weak to distinguish between leverage targeting and other financing motives. See Graham and Leary (2011) for a discussion of these issues. 
debt to accommodate investment spikes. Finally, according to the survey evidence of Graham and Harvey (2001), chief financial officers report that they target a capital structure range but not a specific value. Furthermore, these officers believe that taxes are one of the important determinants of these ranges.

\section{A Traditional Model of Debt Determination}

In this section we present a static capital structure model to derive valuations that are used in Section 4. Let $V_{C}, V_{C S}$, and $V_{C D}$ represent the value of the company's assets, common stock, and debt, respectively, so that $V_{C}$ equals the sum of $V_{C S}$ and $V_{C D}$. Define $Z$ as the cash flow to stock and bond holders:

$$
\mathrm{Z}=(1-\theta) \alpha \mathrm{X}-(1-\theta) \mathrm{rB}-\gamma \mathrm{XB}+\mathrm{rB}=(1-\theta) \alpha \mathrm{X}+\theta \mathrm{rB}-\gamma \mathrm{XB}
$$

where $\mathrm{X}$ represents internal production factors that create cash flow, $\mathrm{B}$ represents bonds, $\theta$ is the tax rate $(\theta>0)$, and $r$ is the interest rate paid on bonds $(r>0)$. The term $\alpha X$ describes a linear production function that converts $\mathrm{X}$ into cash $(\alpha>0)$, and the term $\gamma \mathrm{XB}$ captures the potentially negative aspects of debt on the firm's ability to generate cash flow $(\gamma>0)$ due, for example, to management-creditor conflicts. Thus, the model recognizes in an elementary fashion the existence of debt/corporate decision-making interactions. If the $\gamma \mathrm{XB}$ term is deleted, the model's quantitative results change but its qualitative results remain intact.

Both $\mathrm{X}$ and $\mathrm{B}$ are decision variables whose feasible ranges are as follows: $0 \leq \mathrm{X} \leq \mathbf{X}$ and $0 \leq \mathrm{B} \leq \mathbf{B}$. Assuming a manager/decision-maker maximizes $\mathrm{V}_{\mathrm{C}}$ over an infinite horizon, we have: ${ }^{10}$

$$
\mathrm{V}_{\mathrm{C}}=\mathrm{Z} / \mathrm{r}=[(1-\theta) \alpha \mathrm{X}+\theta \mathrm{rB}-\gamma \mathrm{XB}] / \mathrm{r} .
$$

\section{Model 1:}

Setting the tax rate to zero $(\theta=0)$, akin to Modigliani and Miller (1958) ("MM58" hereafter), we have:

$$
\mathrm{V}_{\mathrm{C}}=[\alpha \mathrm{X}-\gamma \mathrm{XB}] / \mathrm{r}
$$

The first-order conditions for optimal $\mathrm{X}$ and $\mathrm{B}$ are:

$$
\begin{gathered}
\delta \mathrm{V}_{\mathrm{C}} / \delta \mathrm{X}=[\alpha-\gamma \mathrm{B}] / \mathrm{r}, \\
\delta \mathrm{V}_{\mathrm{C}} / \delta \mathrm{B}=[-\gamma \mathrm{X}] / \mathrm{r}<0 .
\end{gathered}
$$

Since ( $3 b$ ) is negative, the optimal level of debt, $B^{*}$, is zero. Thus, consistent with MM58, there is no motive for the firm to issue debt. And since $B^{*} \rightarrow 0, \delta V_{C} / \delta X$ in (3a) is positive and therefore it is value maximizing to set the optimal level of $X, X^{*}$, equal to $X$. Thus the firm's optimal balance sheet is:

$$
\mathrm{V}_{\mathrm{C}}^{*}=\mathrm{V}_{\mathrm{CS}}{ }^{*}+0
$$

Let $\mathrm{P}_{\mathrm{CS}}{ }^{*}(\theta=0)$ represent the market's valuation of the firm's common stock. Since there is no debt, we have:

$$
\mathrm{P}_{C S}^{*}(\theta=0)=\mathrm{V}_{\mathrm{C}}{ }^{*}(\theta=0)=\mathrm{V}_{\mathrm{CS}}{ }^{*}(\theta=0)=\alpha \mathbf{X} / \mathrm{r} \text {. }
$$

10 For simplicity, we assume that the interest rate on bonds is identical to the firm's cost of capital. Footnote 17 discusses alternative assumptions. 


\section{Model 2:}

Setting a positive tax rate $(\theta>0)$ with interest on debt being tax deductable as in MM63 and differentiating $V_{C}$ in (2) with respect to $X$ and $B$ give:

$$
\begin{gathered}
\delta \mathrm{V}_{\mathrm{C}} / \delta \mathrm{X}=[(1-\theta) \alpha-\gamma \mathrm{B}] / \mathrm{r}, \\
\delta \mathrm{V}_{\mathrm{C}} / \delta \mathrm{B}=[\theta \mathrm{r}-\gamma \mathrm{X}] / \mathrm{r} .
\end{gathered}
$$

There are seemingly two solutions, one interior and one corner. However, it can be shown that the interior solution is not viable because it implies a negative common stock price. ${ }^{11}$ For the corner solution, we have

$$
\begin{aligned}
& \delta \mathrm{V}_{\mathrm{C}} /\left.\delta \mathrm{X}\right|_{\mathrm{X}=\mathbf{X}, \mathrm{B}=\mathbf{B}}>0 \Rightarrow \mathrm{B}^{*}=\mathbf{B}, \\
& \delta \mathrm{V}_{\mathrm{C}} /\left.\delta \mathrm{B}\right|_{\mathrm{X}=\mathbf{X}, \mathrm{B}=\mathbf{B}}>0 \Rightarrow \mathrm{X}^{*}=\mathbf{X} .
\end{aligned}
$$

At the corner solution the optimal value of the company's assets is

$$
\mathrm{V}_{C}^{*}(\theta>0)=[\mathbf{X}(1-\theta) \alpha+\theta \mathrm{rB}-\gamma \mathbf{X B}] / \mathrm{r}
$$

The asset value of the company is positive in (7) because the term $[\theta \mathrm{r} \mathbf{B}-\gamma \mathbf{X B}]$ is required to be positive, by the definition of the corner solution for bonds in (6b).

There are two solutions for the market valuation (price) of the common stock under the corner solution, $\mathrm{P}_{\mathrm{CS}}{ }^{*}(\theta>0)$, depending on whether the predetermined corner quantity of bonds is less than or greater than the amount denoted as $\mathrm{B}^{\mathrm{MAX}}$. $\mathrm{B}^{\mathrm{MAX}}$ is derived by setting $\mathrm{P}_{\mathrm{CS}}{ }^{*}(\theta>0)=0$,

$$
\mathrm{P}_{\mathrm{CS}}{ }^{*}(\theta>0)=\mathrm{V}_{\mathrm{CS}}{ }^{*}(\theta>0)=[\mathbf{X}(1-\theta) \alpha-\gamma \mathbf{X B}-\mathrm{rB}(1-\theta)] / \mathrm{r}=0
$$

and solving for $\mathrm{B}$. We obtain the following expression for $\mathrm{B}^{\mathrm{MAX}}$ :

$$
\mathrm{B}^{\mathrm{MAX}}=[\mathbf{X}(1-\theta) \alpha] /[\gamma \mathbf{X}+\mathrm{r}(1-\theta)]
$$

When $\mathrm{B}^{\mathrm{MAX}}<\mathbf{B}$, the optimal capital structure sets bond financing at $\mathrm{B}^{*}=\mathrm{B}^{\mathrm{MAX}}$ and thus $P_{C S} *(\theta>0)=0$. As in MM63, equity financing disappears. Consistent with this capital structure, the optimal value of the company's assets, $\mathrm{V}_{C^{*}}\left(\theta>0 ; \mathrm{B}=\mathrm{B}^{\mathrm{MAX}}\right)$, is also given by (8a). This is the same optimal firm value as derived by MM63's equity-quantity shifting process.

A second optimal capital structure can arise if $\mathbf{B}<\mathrm{B}^{\mathrm{MAX}}$. When this condition is satisfied, the market value of common stock, $\operatorname{PCS}^{*}(\theta>0)$, is positive. Thus, equity and debt coexist and the optimal capital structure is such that $\mathbf{B}<\mathrm{B}^{\mathrm{MAX}}$. This second capital structure arises whenever restrictions are placed on the firm's access to the debt market. Since these restrictions are likely to be prevalent in real-world data, we assume that the second optimal capital structure is applicable to the valuations analyzed in Section $4 .^{12}$

\section{A Debt Model with Recapitalization Costs in the Presence of a Takeover Market}

The analysis in Section 3 implicitly assumes that the cost of recapitalization is zero. When this assumption is satisfied and a positive tax rate is instituted, the firm is predicted to alter its capital structure to attain a level of debt equal to either $\mathrm{B}^{\mathrm{MAX}}$ or B. Consistent with MM63, a capital structure without debt is therefore suboptimal.

11 At the interior solution, $\mathrm{B}^{*}=[(1-\theta) \alpha] \gamma$ and $\mathrm{X}^{*}=\theta \mathrm{r} / \gamma$, which implies that $\mathrm{V}_{\mathrm{CS}}{ }^{*}=-(1-\theta)^{2} \alpha / \gamma<0$.

12 The condition $-\theta \alpha \mathbf{X}+[\theta \mathrm{r}-\gamma \mathbf{X}] \mathbf{B}<0$ ensures that asset values are lower in the presence of taxes than in the non-tax world. The condition is satisfied over the feasible range of $\mathrm{B}, 0<\mathrm{B}<\mathrm{B}^{\mathrm{MAX}}$. 
In this section, we assume that the cost of adjusting debt is positive. ${ }^{13}$ We first show that costly recapitalization weakens the firm's incentive to use leverage. While this implication is rather obvious, a much less intuitive and potentially more substantial reduction in the firm's desire to acquire debt occurs when a takeover market is introduced. Essentially, the takeover market, even though it is located outside of the firm, can nevertheless influence the firm's internal recapitalization decision. This type of external market influence is not present in the traditional models of Section 3, i.e., in MM.

Let $C_{I}$ represent the fixed internal cost of recapitalizing an initially all-equity firm when $\theta>0 .{ }^{14}$ This cost includes the cost of negotiating with outside lenders as well as any internal management costs associated with recapitalization. From (5), the value of an all-equity firm when $\theta>0$ is

$$
\mathrm{V}_{\mathrm{C}}(\theta>0)=[(1-\theta) \alpha \mathrm{X}] / \mathrm{r} \text {. }
$$

To recapitalize, it must be the case that the value of an optimally capitalized firm in (7), minus the cost of recapitalization, must exceed the value of remaining as an all-equity firm:

$$
\mathrm{V}_{\mathrm{C}}^{*}(\theta>0)-\mathrm{C}_{\mathrm{I}}>\mathrm{V}_{\mathrm{C}}(\theta>0) \text {. }
$$

Clearly, $\mathrm{C}_{\mathrm{I}}$ is likely to be firm-dependent at the cross-sectional level. If (10) is not satisfied, then apparently sub-optimal capital structures would seem to be present for a certain class of firms. However, firms with these structures would be optimally financed once the internal recapitalization cost is taken into account.

The standard models in Section 3 and (10) assume that the financial system is a passive participant in firms' optimal debt decisions. The supply of debt is viewed as being perfectly elastic at the interest rate $r$, and there is no organized takeover marketplace. The latter is descriptive of much of the 20th century. However, as the financial system became more integrated, both domestically and internationally, large amounts of cash became available for larger-scale acquisitions. A distinguishing characteristic of the modern takeover marketplace is the presence of participants who can buy a sub-optimally structured firm and recapitalize it as optimally structured at, say, a fixed cost, $\mathrm{C}_{\mathrm{E}} \cdot 15$ From (9), the common stock valuation of the sub-optimal all-equity firm is

$$
\mathrm{P}_{\mathrm{CS}}(\theta>0)=[(1-\theta) \alpha \mathbf{X}] / \mathrm{r} \text {. }
$$

The takeover market processes information efficiently, and thus the takeover-market analyst would know that the total value of the firm, if it were optimally structured, is ${ }^{16}$

$$
\mathrm{V}_{\mathrm{C}}^{*}(\theta>0)=[\mathbf{X}(1-\theta) \alpha+\theta \mathbf{B}-\gamma \mathbf{X B}] / \mathrm{r} .
$$

Assuming the condition, $\mathrm{B}<\mathrm{B}^{\mathrm{MAX}}$, is applicable, the analyst would also know, from (8), that the stock market valuation of the recapitalized firm is ${ }^{17}$

$$
\mathrm{P}_{\mathrm{CS}}^{*}(\theta>0)=[\mathbf{X}(1-\theta) \alpha-\gamma \mathbf{X B}-\mathrm{rB}(1-\theta)] / \mathrm{r}>0 .
$$

13 The model in this section can be regarded as a static costly adjustment model within the more general class of tradeoff models. See Mauer and Triantis (1994) for a model of the interaction between a firm's dynamic investment, operating, and financing decisions in the face of operating adjustment and recapitalization costs. See Fischer et al. (1989) for a model of dynamic capital structure choice in the presence of recapitalization costs.

14 The model can be generalized to include a recapitalization cost function that has a fixed component and a proportional factor that depends on the amount of debt usage. See footnote 17.

15 This fixed cost includes expenses relating to data analysis and trading costs associated with the acquisition of shares.

16 Increasing the level of debt is likely to raise the firm's cost of capital. Let $r_{k}$ represent the cost of capital. If we assume that $r_{k}=r+r_{1}(B)$, the model's quantitative solutions will change but the implications discussed in the paper will remain intact.

17 Clearly the equity market valuation in (11) exceeds that in (12). 
Given the observed price in (11) and the predicted value in (12), a takeover firm can buy the sub-optimally structured firm at $\mathrm{P}_{\mathrm{CS}}(\theta>0)$ and then recapitalize it optimally with equity valued at $\mathrm{P}_{\mathrm{CS}}{ }^{*}(\theta>0)$ in (13) and debt equal to $\mathbf{B}$, bearing the fixed $\operatorname{cost} \mathrm{C}_{\mathrm{E}} \cdot{ }^{18}$ The takeover firm would earn a net profit equal to

$$
\Pi_{\mathrm{PE}}=\mathrm{V}_{\mathrm{C}} *(\theta>0)-\mathrm{P}_{\mathrm{CS}}(\theta>0)-\mathrm{C}_{\mathrm{E}} .
$$

This profit can be rewritten as:

$$
\Pi_{\mathrm{PE}}>0 \Rightarrow \mathbf{B}[\theta \mathrm{r}-\gamma \mathbf{X}]-\mathrm{C}_{\mathrm{E}}
$$

In the presence of a perfectly efficient takeover market, $\Pi_{\mathrm{PE}}$ must be zero in equilibrium. Since $V_{C}^{*}(\theta>0)$ and $C_{E}$ are predetermined in (14), the condition $\Pi_{P E}=0$ requires that the market valuation of the sub-optimal, all-equity firm's common stock must jump to a new level $\mathrm{P}_{\mathrm{CS}}{ }^{\mathrm{E}}(\theta>0)$ where ${ }^{19}$

$$
\mathrm{P}_{C S}{ }^{\mathrm{E}}(\theta>0)=\mathrm{V}_{\mathrm{C}}^{*}(\theta>0)-\mathrm{C}_{\mathrm{E}}
$$

According to (16), the price of the common stock of the sub-optimal firm must approach-via the competitive pressure among participants in the takeover market-the price of an otherwise identically-situated optimally structured firm. ${ }^{20}$ In MM63, a takeover market is not present. As a result, the equilibrium in their model is achieved by a shift in the quantity of equity (to zero). In the model in Section 4, by contrast, equilibrium is achieved by a shift in the price of equity. Again, a blending of these two equilibrating approaches is possible.

The major implication of introducing a takeover market is that the relevant valuation equation for a firm's internal recapitalization decision is not necessarily

$$
\mathrm{V}_{\mathrm{C}}^{*}(\theta>0)-\mathrm{C}_{\mathrm{I}}>\mathrm{P}_{\mathrm{CS}}(\theta>0) \text {, }
$$

as the standard model would suggest. Instead, it also could be

$$
\mathrm{V}_{\mathrm{C}}^{*}(\theta>0)-\mathrm{C}_{\mathrm{I}}>\mathrm{P}_{\mathrm{CS}}^{\mathrm{E}}(\theta>0) .
$$

A blended approach, whereby the new equilibrium capital structure is achieved in part by debt issuance and in part by a shift in equity value, implies a relevant valuation equation determined jointly by the conditions reflected in Equations (17) and (18).

Equation (18) describes a tighter condition on the firm's internal recapitalization decision than (17) whenever $\mathrm{P}_{C S}{ }^{\mathrm{E}}(\theta>0)>\mathrm{P}_{C S}(\theta>0)$. Essentially, the difference between $\mathrm{P}_{C S}{ }^{\mathrm{E}}(\theta>0)$ and $\mathrm{P}_{C S}(\theta>0)$ reflects the takeover market's incorporation of the asset value of the optimally structured firm (minus the

18 Once again, we emphasize that such an acquisition is more likely to occur for smaller firms since less takeover capital (which is in limited supply) is required for these firms. Likewise, we note that the standard tradeoff model requires the debt market to be sufficiently large to absorb a shift in firms' debt utilization. When viewed in this way, the consequences of the standard model-like those of the approach assumed here-also may be tempered by the reality of limited capital.

19 One way to reformulate our model to address the issue of limited takeover capital and its effect on the change in share value is to ascribe a probability $(<1)$ to the takeover market's ability to acquire a sub-optimally capitalized firm's equity. The consequence of such a reformulation is to reduce the jump in share price and, therefore, to retain some of the traditional tradeoff model's requirement of new debt issuance in order for the firm to capture the tax shield. When the ability of the sub-optimally capitalized firm to issue debt is similarly attenuated by introducing an analogous probability reflecting the limited amount of capital available to fund new debt, the overall effect is an inability of firms to collectively capture the entirety of the tax shield. A potentially interesting inquiry concerns which firms capture the interest tax shield and which are left empty-handed in the face of constraints on equity and debt funding available in the takeover and credit markets, respectively.

20 The analysis underlying Equations (11) through (16) can be reworked so that the takeover firm borrows at $\mathrm{r}$, buys the sub-optimal firm, recapitalizes it, and pays back the borrowing the next period. However, the $\Pi_{\mathrm{PE}}>0$ condition becomes more complicated. 
fixed external recapitalization cost, $C_{E}$ ) into the stock valuation of the sub-optimally structured firm. ${ }^{21}$ Whether internal recapitalization would occur in the presence of a takeover market is dependent on the relative levels of internal and external recapitalization costs. ${ }^{22}$ Substituting (16) for $\mathrm{P}_{\mathrm{CS}}{ }^{\mathrm{E}}(\theta>0)$ in (18), internal recapitalization is initiated if

$$
\mathrm{C}_{\mathrm{I}}<\mathrm{C}_{\mathrm{E}}
$$

To interpret (19), at progressively lower levels of $C_{E}$, competition in the takeover market induces a larger jump in the stock price of the all-equity firm, which reduces the firm's calculation of the net benefit of internal recapitalization. ${ }^{23}$ When $C_{E}$ is less than $C_{I}$, the all-equity firm would not consider an internal recapitalization. Moreover, when recapitalization costs are uniformly zero, i.e., $C_{I}=C_{E}=0$, then $\mathrm{V}_{C}{ }^{*}(\theta>0)=\mathrm{P}_{C S}{ }^{\mathrm{E}}(\theta>0)$. Under this extreme cost condition, the apparently sub-optimal all-equity firm and an identical firm that had undergone an optimal capital restructuring would have the same asset values. All of the benefits of the tax shield would have been incorporated into the stock value of the all-equity firm. Hence, our equity-price shifting equilibrating process leads to the same optimal firm value as would be obtained under the original equity-quantity shifting equilibrating process of MM63.

Thus, the existence of a takeover market may create stock market valuations such that the internal recapitalization outcome depends only on the relative size of the internal and external fixed costs of recapitalization (albeit other factors are likely to be determinants, as has been discussed in several footnotes). Empirically, it is likely that internal fixed costs exhibit wider variation than external fixed costs. Thus, some firms with relatively low internal fixed costs will recapitalize and exhibit optimal capital structures, while those with higher internal fixed costs will continue to exhibit sub-optimal capital structures. The sub-optimality, however, is only apparent because the takeover market, in seeking to exploit sub-optimally structured firms, influences stock prices so that the stock valuations of sub-optimally structured firms approach the asset values of optimally structured firms. The rewards of internal recapitalization are received by the stockholders of the all-equity firm, without its initiating any recapitalization. The model therefore predicts that some firms will appear to possess under-leverage and persistently sticky capital structures.

Although the models in this section are static so that price and quantity adjustments are both instantaneous, one can envision a heuristic description of the alternative model's time path for debt usage and equity prices. Consider an unexpected increase in the corporate tax rate and assume that the speed of adjustment in equity prices exceeds that of debt utilization. In the absence of a takeover market, equity prices of all-equity firms decline initially. For one set of firms with large internal recapitalization costs, debt levels remain at zero and equity prices remain at their lower values. For the other set of firms with small $C_{I}$, debt levels optimally rise over time but these firms' equity prices continue to fall because $\mathrm{P}_{C S} *(\theta>0)$ in (8) is less than $\mathrm{V}_{C}(\theta>0)$ in (9). The equity price differential between the two sets of firms would continue to widen over time.

21 In this regard, the model implies that the stock value of a firm that does not recapitalize in the presence of a tax shield is not necessarily determined by the standard discounted cash flow model.

22 Fischer et al. (1989) find that even small recapitalization costs lead to wide swings in a firm's debt ratio over time.

23 Again, this change in equity value could be assigned a probability that reflects the prospect of a takeover. This probability would be less than one due to limits on capital available to finance takeovers. Another reason that the true change in equity value may not be as large as reflected in Equations (17) and (18) is that investors may suspect that a takeover firm will not pass along all or part of the benefits of the tax shield to equity shareholders. For instance, it has been observed that private equity firms retain the surpluses from their takeover activities. [Analogously, one could opine that, under standard tradeoff models, predatory creditors may require that the lion's share of the tax shield be passed along to them (presumably in the form of a higher coupon payment) before they provide the debt capital needed to unlock the tax shield.] The effect of takeover companies retaining all or part of the tax shield has the consequence of reducing the jump in equity value predicted by our model, which in turn requires that part of the shield be captured by the traditional tradeoff model's approach of new debt issuance. 
Now consider the adjustments to the unexpected tax increase when the takeover market is present. As before, the equity prices of all-equity firms would decline but the extent of the decline would be moderated as competitive bidding was initiated by the participants in the takeover market (as well as other investors who anticipate the actions of takeover firms). Given the equilibrium equity price $\mathrm{P}_{C S}{ }^{\mathrm{E}}(\theta>0)$ in (16), the sets of recapitalizing and non-recapitalizing firms would depend on the values of each firm's $C_{I}$ relative to $C_{E}$. Small $C_{I}$ firms would recapitalize and their equity values would drop to $P_{C S} *(\theta>0)$ in (9). The large $C_{I}$ firms would remain all-equity at the equity price $P_{C S}{ }^{E}(\theta>0)$. Thus, the equity price differential between the two sets of firms would also widen over time.

What is the impact of the takeover market when recapitalization costs are present? The qualitative predictions of the models with and without a takeover market are similar. The difference lies in the quantitative predictions. The takeover model relative to the standard model predicts a wider equity price differential between apparently sub-optimal and optimally structured firms and a larger proportion of apparently sub-optimal firms. ${ }^{24}$ The data therefore create a bias against the confirmation of the standard model's hypothesis, because that model is not completely applicable when the takeover market is involved in the restructuring decision and thus in the creation of the data.

\section{Conclusions}

Modigliani and Miller (1963) present an equity-quantity shifting equilibrating process to achieve optimal firm value in the presence of corporate taxes. In this paper we provide an alternative equilibrating process. Specifically, we provide a partial equilibrium debt tradeoff model with recapitalization costs in which apparently sub-optimal capital structures can persist for a cohort of firms, even in the absence of any interaction between debt and other aspects of corporate decision-making. Most importantly, we also show that the existence of a takeover market can alter stock market valuations such that some firms may find it optimal not to recapitalize, even though the standard discounted cash flow model with recapitalization costs predicts that they should recapitalize. The difference between our model and a standard tradeoff model is that the former incorporates the capital-structure equilibrating influence of the presence of a takeover market in addition to that of a debt market, whereas the latter only facilitates the equilibrating influence of a debt market. In this sense, the original MM framework represents a nested version of the framework presented herein. The relative contributions of the two equilibrating influences likely depend on a broad set of factors (including recapitalization costs as well as those identified in footnote 25). The takeover model we present therefore may help to provide broader insights into the under-leverage and sticky debt puzzles and point to a new direction for conducting empirical work on capital structures.

Given that trade-off theory dominated the capital structure literature-and corporate financial practice-for 40 years, it is important to demonstrate that the M\&M equilibrium is not unique. In particular, this issue should be a key consideration in decision making involved in business valuation and capital structure-from the perspectives of different stakeholders, including analysts, corporate financial officers, and creditors.

For valuation, because of our findings, analysts may need to adjust their idea of what constitutes an optimal capital structure, and the valuation consequences thereof for the firm's stock price. What at first appears to be an under-leveraged firm may not be the case, because the stock price already reflects the ability to lever up, and vice versa. So, analysts' stock price forecasts and buy-sell recommendations may have to be reevaluated in light of our equilibrium.

In a related manner, a corporate financial officer may need to modify what constitutes the firm's target capital structure. The whole idea of a "target" is undermined—at least somewhat—by our

24 Again, the sizes of the equity price differential and the proportion of apparently sub-optimally capitalized firms depend on additional factors such as the size of the firm, its voting rights/controlling interest, the availability of equity takeover capital, the availability of capital to purchase new debt, the likelihood that the plausible jump in equity value will be passed along to shareholders by the takeover firm, and the demands of new creditors regarding their share of the benefits of the tax shield. 
finding of a stock-price adjusting equilibrium. There is a large literature regarding targeting. Indeed, most of the current empirical studies regarding debt use focus on a "distance" measure-namely how far is the firm's capital structure from its target. This entire literature may need to be reassessed in light of our theory.

For creditors, our finding raises the fundamental question of what constitutes too much leverage. This question has obvious implications for whether to extend credit, whether to restructure existing credit, etc. Is a firm really under-levered to extend credit when the takeover market has the ability to restructure the debt?

Finally, our theoretical work also has important policy implications. Under the trade-off theory, Congress has a tool to change aggregate firm leverage; changing the debt interest deductions incentivizes firms to change their debt use. Our paper suggests that this tool is more complicated than the traditional theory suggests, because the leverage change is not necessarily achieved via debt level changes.

Acknowledgments: We thank seminar participants at the School of Management, Fudan University (Shanghai), and Peking University's HSBC School of Business (Shenzhen), for helpful comments.

Author Contributions: Authors contributed equally.

Conflicts of Interest: The authors declare no conflicts of interest.

\section{References}

Almeida, Heitor, and Thomas Philippon. 2007. The risk-adjusted cost of financial distress. Journal of Finance 62: 2557-86. [CrossRef]

Baker, Malcolm, and Jeffrey Wurgler. 2002. Market timing and capital structure. Journal of Finance 57: 1-30. [CrossRef]

DeAngelo, Harry, and Ronald W. Masulis. 1980. Optimal capital structure under corporate and personal taxes. Journal of Financial Economics 8: 3-29. [CrossRef]

DeAngelo, Harry, Linda DeAngelo, and Toni M. Whited. 2011. Capital structure dynamics and transitory debt. Journal of Financial Economics 99: 235-61. [CrossRef]

Desai, Mihir A., and Dhammika Dharmapala. 2009. Corporate tax avoidance and firm value. Review of Economics and Statistics 91: 537-46. [CrossRef]

Fama, Eugene F., and Kenneth R. French. 2002. Testing tradeoff and pecking order predictions about dividends and debt. The Review of Financial Studies 15: 1-33. [CrossRef]

Fischer, Edwin O., Robert Heinkel, and Josef Zechner. 1989. Dynamic capital structure choice: Theory and tests. Journal of Finance 44: 19-40. [CrossRef]

Flannery, Mark J., and Kasturi P. Rangan. 2006. Partial adjustment toward capital structure. Journal of Financial Economics 79: 469-506. [CrossRef]

Graham, John R. 2000. How big are the tax benefits of debt? Journal of Finance 55: 1901-41. [CrossRef]

Graham, John R., and Campbell R. Harvey. 2001. The theory and practice of corporate finance: Evidence from the field. Journal of Financial Economics 60: 186-243. [CrossRef]

Graham, John R., and Mark T. Leary. 2011. A review of empirical capital structure research and directions for the future. Annual Review of Financial Economics 3: 309-45. [CrossRef]

Graham, John R., and Krishnamoorthy Narasimhan. 2004. Corporate Survival and Managerial Experiences during the Great Depression. Working Paper. Durham: Duke University.

Graham, John R., and Alan L. Tucker. 2006. Tax shelters and corporate debt policy. Journal of Financial Economics 81: 563-94. [CrossRef]

Graham, John R., Mark H. Lang, and Douglas A. Shackelford. 2004. Employee stock options, corporate taxes, and debt policy. Journal of Finance 59: 1585-618. [CrossRef]

Green, Richard C., and Burton Hollifield. 2003. The personal tax advantages of equity. Journal of Financial Economics 67: 176-216. [CrossRef]

Grier, Paul, and Paul Strebel. 1980. The empirical relationship between taxation and capital structure. Financial Review 15: 45-57. [CrossRef]

Hennessy, Christopher A., and Toni M. Whited. 2005. Debt dynamics. Journal of Finance 60: 1129-65. [CrossRef] 
Huizinga, Harry, Luc Laeven, and Gaetan Nicodeme. 2008. Capital structure and international debt shifting. Journal of Financial Economics 88: 80-118. [CrossRef]

Ju, Nengjiu, Robert Parrino, Allen M. Poteshman, and Michael S. Weisbach. 2005. Horses and rabbits? Optimal dynamic capital structure from shareholder and manager perspectives. Journal of Financial and Quantitative Analysis 40: 259-81. [CrossRef]

Kayhan, Ayla, and Sheridan Titman. 2007. Firms' histories and their capital structures. Journal of Financial Economics 83: 1-32. [CrossRef]

Leary, Mark T., and Michael R. Roberts. 2005. Do firms rebalance their capital structure? Journal of Finance 60: 2575-619. [CrossRef]

Lemmon, Michael L., Michael R. Roberts, and Jaime F. Zender. 2008. Back to the beginning: Persistence and the cross-section of corporate capital structure. Journal of Finance 63: 1575-608. [CrossRef]

Lin, Shannon, Naqiong Tong, and Alan L. Tucker. 2014. Corporate tax aggression and debt. Journal of Banking and Finance 40: 227-41. [CrossRef]

Mauer, David C., and Alexander J. Triantis. 1994. Interactions of corporate financing and investment decisions: A dynamic framework. Journal of Finance 49: 1253-77. [CrossRef]

Miller, Merton H. 1963. The Corporate Income Tax and Corporate Financial Policies. In Commission on Money and Credit, Stabilization Policies. Englewood Cliffs: Prentice-Hall.

Miller, Merton H. 1977. Debt and taxes. Journal of Finance 32: 261-75.

Modigliani, Franco, and Merton H. Miller. 1958. The cost of capital, corporation finance and the theory of investment. American Economic Review 48: 261-97.

Modigliani, Franco, and Merton H. Miller. 1963. Corporate income taxes and the cost of capital: A correction. American Economic Review 53: 433-43.

Morellec, Erwan, and Norman Schürhoff. 2010. Dynamic investment and financing under personal taxation. Review of Financial Studies 23: 101-46. [CrossRef]

Parrino, Robert, and Michael S. Weisbach. 1999. Measuring investment distortions arising from stockholder-bondholder conflicts. Journal of Financial Economics 53: 3-42. [CrossRef]

Rauh, Joshua D., and Amir Sufi. 2010. Capital structure and debt structure. Review of Financial Studies 23: 4242-80. [CrossRef]

Sametz, Arnold W. 1964. Trends in the volume of composition of equity finance. Journal of Finance 19: 450-69.

Shivdasani, Anil, and Irina Stefanescu. 2010. How do pensions affect corporate capital structure decisions? Review of Financial Studies 23: 1287-23. [CrossRef]

Taggart, Robert A., Jr. 1985. Secular Patterns in the Financing of US Corporations. In Corporate Capital Structures in the United States. Edited by Benjamin M. Friedman. New York: University of Chicago Press, pp. 13-80.

Tserlukevich, Yuri. 2008. Can real options explain financing behavior? Journal of Financial Economics 89: $232-52$. [CrossRef]

Welch, Ivo. 2004. Capital structure and stock returns. Journal of Political Economy 112: 106-31. [CrossRef]

Welch, Ivo. 2011. Two common problems in capital structure research: The financial-debt-to-asset ratio and issuing activity versus leverage changes. International Review of Finance 11: 1-17. [CrossRef]

(C) 2018 by the authors. Licensee MDPI, Basel, Switzerland. This article is an open access article distributed under the terms and conditions of the Creative Commons Attribution (CC BY) license (http://creativecommons.org/licenses/by/4.0/). 